\title{
Development of serum-free culture systems for the ruminant embryo and subsequent assessment of embryo viability
}

\author{
D. K. Gardner \\ Colorado Center for Reproductive Medicine, 799 East Hampden Ave, Suite 300, Englewood, \\ CO 80110, USA
}

\begin{abstract}
The mammalian embryo undergoes considerable changes in its physiology and energy metabolism as it proceeds from the zygote to the blastocyst stage. Complete development of the mammalian zygote in vitro was restricted to a few strains of mice and their F1 hybrids for many years, as the ruminant embryo arrested development at the 8- to 16-cell stage. The introduction of co-culture of ruminant embryos with somatic cells in the mid-1980s helped to alleviate this in vitro induced arrest. However, such culture systems required the use of complex tissue culture media and serum. Serum has subsequently been shown to induce several abnormalities during embryo development in culture and has been associated with the production of offspring with significantly greater birth weights than normal, leading to both difficulties in pregnancy management and an unacceptable frequency of neonatal death. Resurgence of interest in mammalian embryo physiology has culminated in the formulation of defined embryo culture media, capable of supporting a high percentage of viable blastocyst development in vitro. Optimum embryo development in culture has been shown to take place not in one, but two or more media, each designed to cater for the changing requirements and metabolism of the embryo as it develops. The development of viability assays to identify those embryos with the highest developmental potential will further increase the efficiency of embryo transfer procedures. Assays based upon nutrient uptake and subsequent utilization make promising candidates.
\end{abstract}

\section{Introduction}

Before attempting to culture any cell type, be it embryonic or somatic, it is important to consider the physiology of the cell to establish its nutrient requirements. The mammalian embryo therefore poses an intriguing problem in that its physiology changes during the preimplantation period. Subsequently, nutrient requirements by the embryo also change with successive stages of development. In parallel with such changes in nutrient requirements of the embryo, the environment to which the embryo is exposed in the female reproductive tract differs as the embryo progresses through the oviduct to the uterus. Data are emerging that show that embryo development in culture and maintenance of viability is facilitated not by a single culture medium, but rather by the use of sequential media that provide for the different requirements of the developing embryo. The ability to maintain the embryos of sheep and cattle in culture without compromising developmental potential will greatly expedite the development and introduction of procedures such as transgenesis and cloning.

\section{Nutrient Requirements and Metabolism}

Changes in physiology as the embryo develops are reflected in different nutrient requirements and energy metabolism. The significance of energy metabolism during embryo development cannot be 
understated, as impairment of metabolism is associated with developmental delay or even arrest (Gardner, 1998a). Indeed embryo development will not occur in the absence of exogenous substrates. Successful early embryo development is therefore dependent upon the ability of the embryo to generate energy through the appropriate metabolic pathway(s) at specific times during the preimplantation period (Gardner, 1998a). The ruminant embryo before compaction exhibits low levels of oxidative metabolism and oxygen consumption, whereas the later stages (i.e. after compaction) exhibit both high levels of glycolysis and high oxygen consumption (Thompson et al, 1996). The ruminant embryo has a limited capacity to utilise glucose until after compaction (Tiffin et al., 1991; Rieger et al., 1992; Thompson et al., 1992a; Gardner et al., 1993). Up to this stage of development, plasma concentrations of glucose can be detrimental to early mammalian embryo development in specific culture conditions (Thompson et al, 1992a). Accordingly, the early embryo utilises pyruvate and lactate alone or in combination with amino acids (Leese, 1991; Gardner and Lane, 1993a) to generate the required energy. The relatively low level of metabolism in the pre-compacted embryo reflects the quiescent state of the oocyte, which remains energetically relatively dormant within the ovary. As the oocyte and zygote have relatively low levels of biosynthesis before embryonic genome activation and expression, there will be a high ATP:ADP ratio within the blastomeres, which will in turn allosterically reduce the flux through the glycolytic pathway. As the embryo becomes increasingly transcriptionally active and protein synthesis increases, and as the blastocoel is formed through the action of the basolateral ATPases, the ATP:ADP ratio will fall and an increased glycolytic flux will become possible (Gardner, 1998a). Indeed, glucose metabolism by both sheep and cattle embryos increases with development, with the highest rates of utilization occurring at the blastocyst stage (Tiffin et al., 1991; Rieger et al., 1992; Thompson et al., 1992a+ Gardner et al. 1993).

In the blastocyst of primates and rodents, the high levels of glucose conversion to lactate even in the presence of adequate concentrations of oxygen for oxidative metabolism (termed 'aerobic glycolysis'), have been interpreted as the adaptation of the embryo to its imminent invasion of the endometrium. As the ruminant blastocyst does not attach to the endometrium for several days after entry into the uterus, alternative explanations for this type of metabolism are required. It is plausible that the oxygen tension within the ruminant uterus is very low, and so glycolysis represents an adaptation of the blastocyst to such conditions. Alternatively, a high level of aerobic glycolysis is a common characteristic of rapidly dividing cells and tumours (Rieger, 1992; Gardner, 1998b). As well as being used to generate energy for blastocoel expansion and mitosis, glucose is therefore required for the synthesis of triacylglycerols and phospholipids and as a precursor for complex sugars of mucopolysaccharides and glycoproteins. Glucose metabolized by the pentose phosphate pathway (PPP) generates ribose moieties required for nucleic acid synthesis and the NADPH required for the biosynthesis of lipids and other complex molecules. NADPH is also required for the reduction of intracellular glutathione, an important antioxidant for the embryo (Rieger, 1992). The production of nucleic acids is probably an important biosynthetic role of glucose in the blastocyst. As the ruminant blastocyst undergoes considerable expansion prior to attachment, it is feasible that high glucose flux through glycolysis will ensure that there is sufficient substrate available for biosynthetic pathways, such as DNA replication, RNA transcription and synthesis of new membranes, at the required times during cellular proliferation. This suggests that there may be times within the cell cycle during which the PPP is more active than others.

The mammalian embryo possesses a considerable degree of plasticity and can adapt to the absence of one substrate by increasing its utilization of others (Gardner 1998a). Furthermore, inadequate culture conditions in vitro induce serious metabolic aberrations in the embryo, whereby the pattern of energy metabolism is significantly different from that of embryos developed in vivo. The more unphysiological the culture conditions are, the greater the metabolic stress placed on the embryo, which in turn is associated with loss of developmental competence (Gardner, 1998a).

\section{Culture of the Ruminant Embryo}

Tervit et al, (1972) demonstrated that by formulating a simple culture medium (Synthetic Oviduct Fluid, SOF) based upon the concentrations of ions and carbohydrates present in sheep oviduct fluid 
(Restall and Wales, 1966), it was possible to observe development of the early sheep and cow embryo to the morula or blastocyst stage in culture. However, this approach was not widely adopted. Rather the embryos of sheep and cattle were routinely transferred to the ligated oviduct of either a rabbit or sheep. Such an approach was deemed more physiological. In an attempt to reproduce conditions similar to those in vivo, Gandolfi and Moor (1987) used a monolayer of epithelial cells taken from the sheep oviduct to support the development of sheep embryos. When such a co-culture approach was used $42 \%$ of the embryos reached the blastocyst stage. Following on from this work, the beneficial effects of co-culture were reported for the goat and cow (Sakkas et al., 1989; Wiemer et al., 1991). However, the media used in co-culture systems were designed to maintain specific somatic cell lines in culture and were not designed for the requirements of the embryo. Furthermore, such co-culture systems required the presence of serum to keep the somatic cells viable. Two points arise directly from this: first, the media used in co-culture systems do not themselves support embryo development per se, and secondly the use of whole serum has serious consequences for subsequent fetal development (see below). In spite of this, co-culture has been adopted widely as a routine culture system, and the resultant fetal oversize and neonatal deaths have become accepted costs of this approach (Behboodi et al., 1995).

Interestingly, the oxygen concentration within the lumen of the female reproductive tract (3-8\%; Mastroianni and Jones, 1965; Fischer and Bavister, 1993) is significantly lower than that present in air $(20 \%)$. In line with these physiological data, development of ruminant embryos in culture is significantly increased when the oxygen concentration is between 5 and $10 \%$ compared with $20 \%$. This was the first factor identified that allowed embryo development in a simple medium such as SOF (Tervit et al., 1972; Thompson et al., 1990; Batt et al., 1991). Indeed it is plausible that reducing the oxygen tension in the vicinity of the embryo is one mechanism by which somatic cells can confer benefit to the embryo in a co-culture system (Edwards et al., 1997).

There appears to have been a north-south divide regarding the choice of culture system for the ruminant embryo. In Australia and New Zealand, unlike the United States and Europe, co-culture has not been the culture system of choice. Rather the SOF medium has been used extensively. Thompson et al. (1992b) and Walker et al. (1992) both reported that the supplementation of SOF with human serum could support high rates of blastocyst development ( 80 to $90 \%$ ) from the culture of 1 and 2-cell sheep embryos for 5 days in vitro. Furthermore, such blastocysts were shown to have a high viability with $70-80 \%$ of embryos transferred surviving to term. However, similar to the use of co-culture systems, a $37 \%$ post-natal mortality rate was observed, most likely due to the high birth weight of the dead lambs. Recent data on the sheep embryo have shown that it is the serum in the culture media that adversely affects embryo development in a number of ways: precocious blastocoel formation (Walker et al., 1992; Thompson et al., 1995), sequestration of lipid (Thompson et al., 1995), abnormal mitochondrial ultrastructure (Thompson et al., 1995) and perturbations in metabolism (Gardner et al., 1994). Indeed, embryos cultured in the presence of serum have very different morphologies from those cultured in its absence (Fig. 1). However, it was the finding that the presence of serum in the culture system was associated with abnormally large offspring in sheep that is of greatest significance (Thompson et al., 1995). The mechanism by which serum induces these aberrations remains to be resolved. However, the role of growth factors in serum in inducing altered patterns of development, and in the overexpression of growth factor genes cannot be overlooked.

\section{Removal of Serum, Moving Towards Defined Culture Media}

The key to the successful replacement of serum in ruminant embryo culture systems was the supplementation of the SOF medium with BSA (fatty-acid free) and amino acids (SOFaa). Oviduct and uterine fluids of mammals are characterized by high concentrations of free amino acids (Miller and Schultz, 1987; Moses et al., 1997). Specifically, the amino acids alanine, aspartate, glutamate, glycine, serine and taurine are present at high concentrations. The fact that both oocytes and embryos possess specific transport systems for amino acids, readily take up amino acids from the surrounding culture medium, and maintain an endogenous pool of amino acids indicates that 

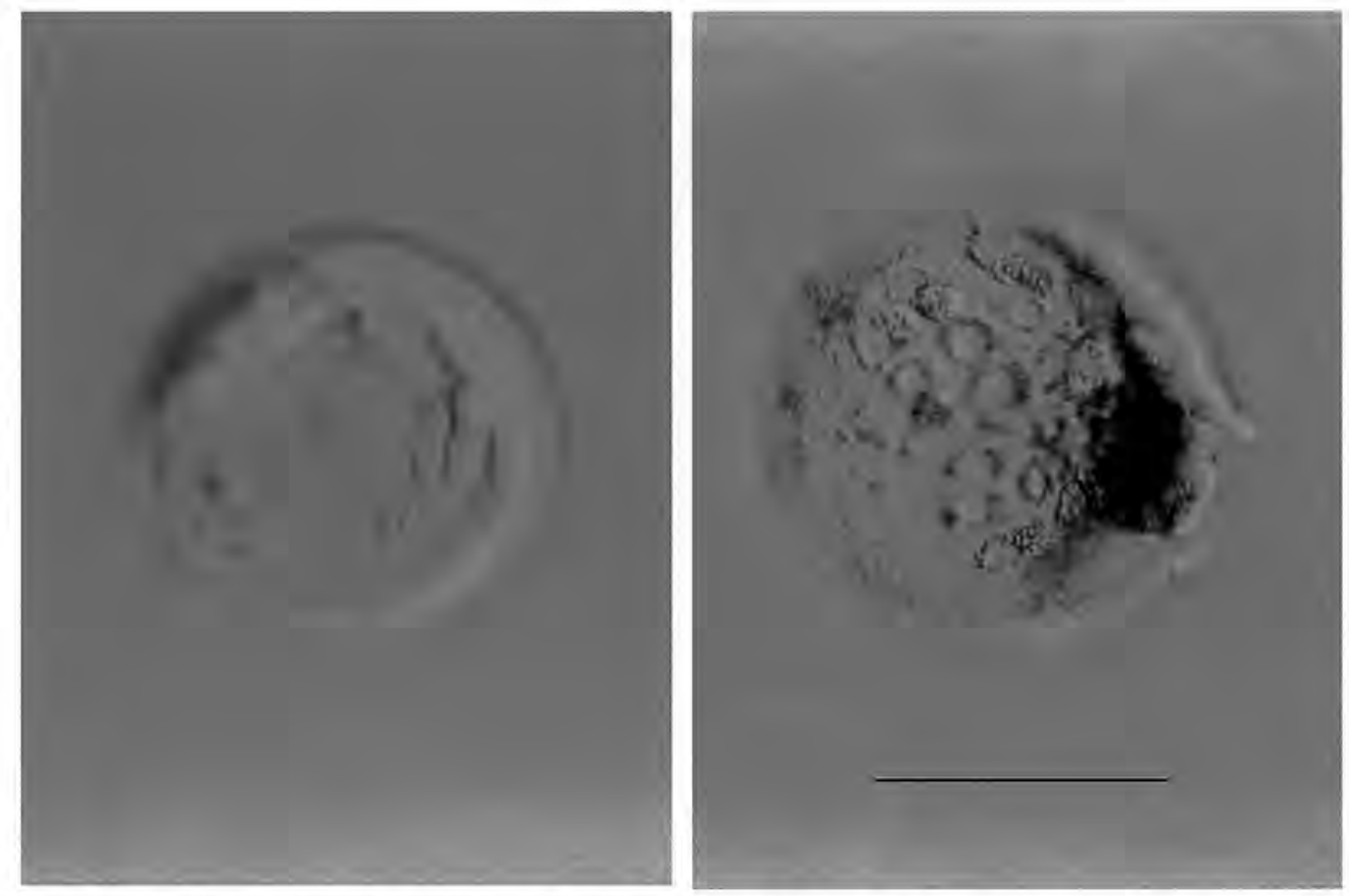

Fig. 1. (a) Sheep blastocyst cultured from the zygote in synthetic oviduct fluid medium supplemented with all 20 of Eagle's amino acids (SOFaa $+8 \mathrm{mg} \mathrm{BSA} \mathrm{ml}^{-1}$ ). Note the translucent appearance of the trophectoderm. (b) Sheep blastocyst (sibling of that shown in Fig 1a) cultured from the zygote in SOF medium supplemented with $20 \%$ human serum. The trophectoderm exhibits many vesicular inclusions, which have been shown to be lipid through osmium staining. Scale bar represents $100 \mu \mathrm{m}$. From Gardner (1994) with permission.

amino acids have a physiological role in the preimplantation period of mammalian embryo development (Gardner and Lane, 1993b). The inclusion of Eagle's amino acids in SOF medium significantly increased the development of sheep and cattle zygotes to the blastocyst stage in culture (Gardner, 1994; Gardner et al., 1994). In a study on sheep zygotes fertilized in vivo, $95 \%$ of blastocyst formation on day 6 of culture was obtained, compared with $67 \%$ when the SOF medium lacked amino acids and was supplemented with $20 \%$ human serum. Furthermore, $79 \%$ of the blastocysts hatched after culture in SOFaa medium. The mean number of cells of such blastocysts $(173 \pm 6)$ was equivalent to control blastocysts developed in vivo $(160 \pm 9)$, in contrast to the number of cells of blastocysts cultured in SOF without amino acids (75 \pm 7$)$. More importantly, the viability of blastocysts cultured with amino acids was equivalent to that of embryos developed in vivo (Gardner et al., 1994). When this culture system was used for the development of IVM/IVF cattle embryos, about $50 \%$ of fertilized oocytes reached the blastocyst stage after just 6 days of culture, day 7 of development (Gardner, 1994; Edwards et al., 1997). Furthermore, the calving rate of these blastocysts was $55 \%$ (Gardner, 1994). The typical morphology of cattle blastocysts derived from the in vitro maturation and in vitro fertilization of oocytes, followed by culture for 6 days in SOFaa medium, is shown (Fig. 2). Similarly, Rosenkrans and First (1994) observed that the addition of the amino acids present in either Eagle's minimum essential medium or those in Eagle's basal medium to the culture medium CR1 increased development of cattle embryos to the blastocyst stage in culture. Liu and Foote (1995) using the culture medium KSOM (Lawitts and Biggers, 1992) found that Eagle's nonessential amino acids with essential amino acids (at half the concentration used by Eagle) gave greatest cow blastocyst development. The composition of these different media have been reviewed 

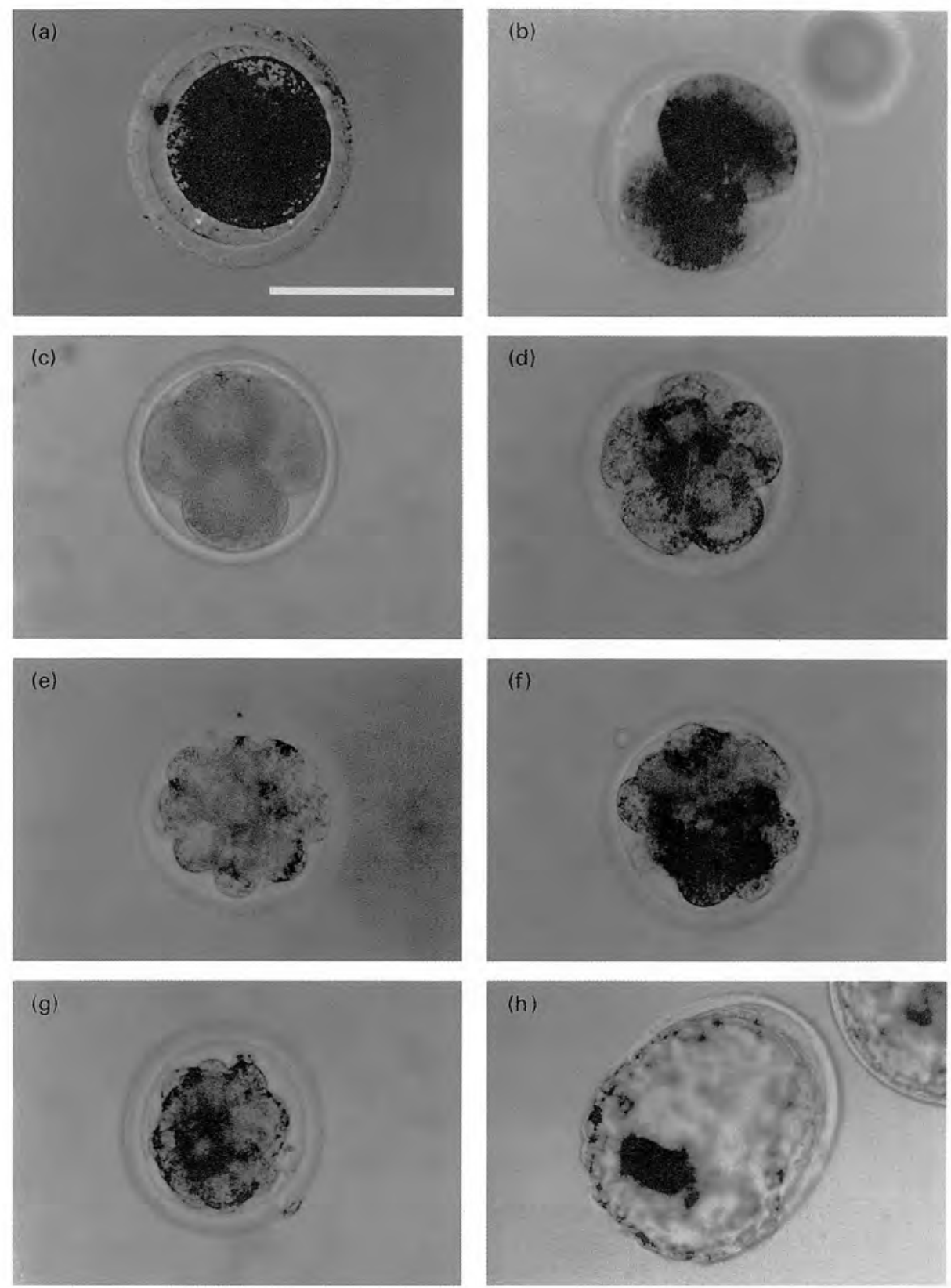

Fig. 2. Temporal development of cattle embryos in culture. Embryos were grown in synthetic oviduct fluid medium supplemented with all 20 of Eagle's amino acids (SOFaa $+8 \mathrm{mg} \mathrm{BSA} \mathrm{ml}^{-1}$ ). (a) Denuded fertilized oocyte $20 \mathrm{~h}$ post insemination (PI). Scale bar represents $100 \mu \mathrm{m}$. (b) Twocell embryo, at $32 \mathrm{~h}$ PI. (c) Four-cell embryo at $44 \mathrm{~h}$ PI. (d) Eight-cell embryo at $68 \mathrm{~h}$ PI. (e) 16-cell embryo at $92 \mathrm{~h}$ PI. (f) 16- to 32-cell embryo undergoing the initial phase of compaction at about $116 \mathrm{~h}$ PI. (g) Morula at $140 \mathrm{~h}$ PI. (h) Expanded hatching blastocyst at $168 \mathrm{~h}$ PI (6 days of culture from the zygote). Note the inner cell mass in the bottom left of the blastocoel. Reproduced from Gardner (1998b) with permission. 
elsewhere (Thompson, 1996; Gardner 1998b), and their ability to support embryo development is shown (Table 1).

The mammalian embryo appears to undergo a switch in its amino acid requirement as development proceeds. In both cattle and mice, the pre-compacted embryo development is faster in the presence of Eagle's non-essential amino acids and glutamine (Gardner and Lane, 1993b; Steeves and Gardner, 1997) (Fig. 3). Beneficial effects of this group of amino acids may well be attributable to their protective role in maintaining cellular function. Amino acids can act as osmolytes to protect against ionic stress (Lawitts and Biggers, 1992), and as regulators of intracellular $\mathrm{pH}$ and metabolism (Gardner and Lane, 1997). After compaction, embryo development is enhanced by the inclusion of all 20 amino acids. It has been shown in the mouse that while the non-essential amino acids stimulate the trophectoderm and glutamine stimulates hatching, the inclusion of essential amino acids causes an increase in the number of inner cell mass cells (Lane and Gardner, 1997b).

A cautionary note when dealing with amino acids in embryo culture media is that they are labile in solution at $37^{\circ} \mathrm{C}$, the result of which is the release of ammonium into the medium (Gardner and Lane, 1993b). It is therefore very important that this toxicity is alleviated for optimum embryo growth to occur by renewing the culture medium every $48 \mathrm{~h}$ (mouse and human) or $72 \mathrm{~h}$ (sheep and cattle).

For defining culture media completely, alternatives to BSA, such as PVA (Pinyopummintr and Bavister, 1991; Liu and Foote, 1995; Keskintepe and Brackett, 1996) and hyaluronate (Gardner et al., 1997a; Kano et al., 1998), have also been used in the extended culture of embryos. However, embryos cultured in the presence of PVA do differ biochemically from those cultured in the presence of BSA (Thompson et al., 1998). The suitability of different macromolecules therefore awaits extensive field trials.

\section{Embryo Grouping}

It has been demonstrated in several species that the culture of embryos in reduced volumes of medium or in groups significantly increases blastocyst development (Paria and Dey, 1990; Lane and Gardner, 1992) as well as increasing the number of blastocyst cells (Paria and Dey, 1990; Lane and Gardner, 1992; Gardner et al., 1994) (Fig. 4a). More importantly, however, culturing embryos in reduced volumes increases subsequent viability after transfer (Lane and Gardner, 1992). It has been proposed that the beneficial effects of growing embryos in small volumes and groups is due to the production of autocrine/paracrine factor(s) by the embryos that stimulate their own development or that of surrounding embryos. Therefore, culture in large volumes results in a dilution of the factor so that it becomes ineffectual (Gardner, 1994). Furthermore, decreasing the incubation volume:embryo ratio specifically stimulates the development of the inner cell mass (ICM). Both mouse and cow blastocysts cultured in a reduced incubation volume:embryo ratio had significantly more ICM cells than those cultured in large volumes, whereas the number of trophectoderm cells was unaffected (Gardner et al., 1997c; Ahern and Gardner, 1998) (Fig. 4b). These findings explain the increased viability of embryos cultured in reduced volumes or groups (Lane and Gardner, 1992). It is plausible that this effect is manifest through a specific embryo derived factor(s). Possible candidates for such autocrine/paracrine factor(s) include platelet-activating factor and insulin-like growth factor II (O'Neill, 1997).

\section{Sequential Embryo Culture Media}

The changes in carbohydrate metabolism and amino acid requirement during development support the application of sequential culture media. In vivo carbohydrate concentrations in the fluid of the female tract change with the day of the oestrous or menstrual cycle (Nichol et al., 1992; Gardner et al., 1996a). Sequential media have been shown to improve embryo development and viability markedly in both mice (Gardner and Lane, 1996; Lane and Gardner, 1997) and humans (Gardner et al., 1998). Results show that sequential media also confer benefit to both sheep (Steeves and Gardner, 1997) 
Table 1. Development of in vitro produced cattle embryos in different culture system

\begin{tabular}{|c|c|c|c|c|}
\hline $\begin{array}{l}\text { Culture } \\
\text { system }\end{array}$ & Reference & $\begin{array}{c}\% \text { Blastocyst } \\
\text { from cleaved } \\
\text { oocytes }\end{array}$ & $\begin{array}{l}\text { Blastocyst } \\
\text { cell number }\end{array}$ & $\begin{array}{c}\text { Number of } \\
\text { days in culture }\end{array}$ \\
\hline $\begin{array}{l}\text { Co-culture with } \\
\text { bovine oviduct } \\
\text { epithelial cells } \\
\text { and serum }\end{array}$ & $\begin{array}{l}\text { Wiemer et al, } \\
\text { (1991) }\end{array}$ & 47 & nd & 8 \\
\hline HECM & $\begin{array}{l}\text { Pinyopummintr } \\
\text { and Bavister (1991) }\end{array}$ & 10 & nd & 8 \\
\hline SOFaa with BSA & $\begin{array}{l}\text { Gardner (1994) } \\
\text { Edwards et al. (1997) }\end{array}$ & $\begin{array}{l}45 \\
64\end{array}$ & $\begin{array}{r}123 \\
97\end{array}$ & $\begin{array}{l}6 \\
6\end{array}$ \\
\hline SOFaa with PVA & Keskintepe et al. (1995) & 50 & nd & 6 \\
\hline $\begin{array}{l}\text { KSOM with PVA } \\
\text { First } 48 \mathrm{~h} \text { in KSOM with } \\
\text { no amino acids } \\
\text { followed by culture in KSOM } \\
\text { with amino acids for } 6 \text { days }\end{array}$ & Liu and Foote (1995) & 41 & nd & 8 \\
\hline $\begin{array}{l}\text { mHECM- } 3 \\
\text { with lactate, } 11 \\
\text { amino acids and } \\
\text { PVA for } 2 \text { days } \\
\text { followed by culture in TCM } \\
199+10 \% \text { bovine serum for } 6 \text { days }\end{array}$ & $\begin{array}{l}\text { Pinyopummintr } \\
\text { and Bavister (1996) }\end{array}$ & 41 & nd & 8 \\
\hline
\end{tabular}

HECM: hamster embryo culture medium; SOFaa: synthetic oviduct fluid with amino acids; KSOM: simplex optimized medium; mHECM3: modified hamster embryo culture medium version 3; PVA: polyvinyl alcohol. From Gardner (1998) with permission.

and cow (Gardner et al., 1997b) embryos in culture. In the case of the cow embryo, this can be demonstrated clearly by the addition of EDTA to the culture medium. The inclusion of EDTA in the culture medium for the first $72 \mathrm{~h}$ prevents 'metabolic transformation' (Gardner, 1998a), by suppressing glycolytic activity. However, should EDTA be present for the second $72 \mathrm{~h}$ of culture to the blastocyst stage, it impairs embryo development, specifically reducing inner cell mass development (Fig. 5). The mechanism by which EDTA acts has been discussed elsewhere (Gardner and Lane, 1997; Gardner, 1998a). In summary, culture conditions, which support optimal development of the zygote, do not support good development and differentiation of the blastocyst. Conversely, those conditions, which favour blastocyst development and differentiation, are detrimental to the zygote (Gardner and Lane, 1997). Ultimately, with the use of perfusion culture (Thompson, 1996), it will be possible to expose the embryo to a number of nutrient gradients in culture, while at the same time being able to remove toxins such as ammonium that are generated in a static system.

\section{Quality Control}

For the successful development and use of defined embryo culture media, it is paramount that the laboratory has a most rigorous quality control system. In a co-culture system both the somatic cells and serum undoubtedly help to remove any toxins present, thereby conferring a greater degree of tolerance to the system. Until defined media become commercially available, it is essential to run bioassays on each new component of the culture system. The most suitable bioassay for any media is the cell type that is being grown. However, in the case of domestic animal embryos this is not always feasible or economical. Therefore, an alternative is the use of a mouse embryo bioassay (Gardner and Lane, 1993a; 1997). In such a bioassay each medium component can be screened for toxicity by 


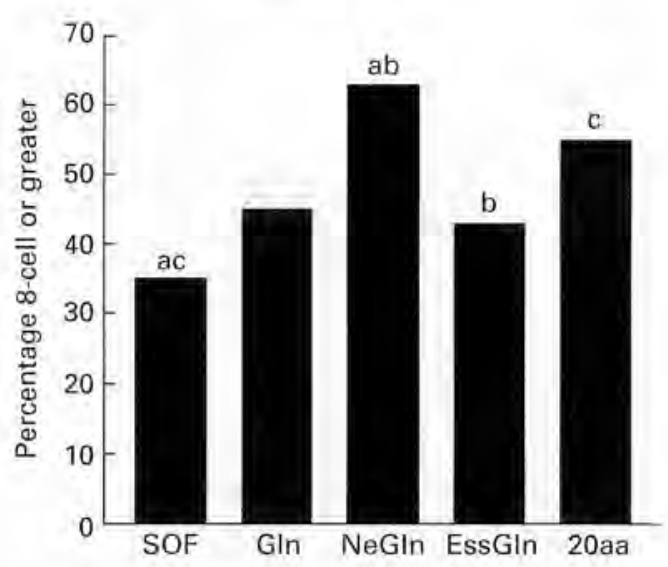

Fig. 3. Development of in vitro matured and in vitro fertilized bovine embryos. SOF (synthetic oviduct fluid with $8 \mathrm{mg} \mathrm{BSA} \mathrm{ml}^{-1}$ ); GIn (synthetic oviduct fluid with $8 \mathrm{mg} \mathrm{BSA} \mathrm{ml}^{-1}+1 \mathrm{mmol}$ glutamine $\left.\mathrm{l}^{-1}\right)$; $\mathrm{NeGln}$ (synthetic oviduct fluid with $8 \mathrm{mg} \mathrm{BSA} \mathrm{ml}^{-1}$

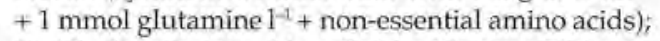
EssGln (synthetic oviduct fluid with $8 \mathrm{mg} \mathrm{BSA} \mathrm{ml}^{-1}$ +1 mmol glutamine $^{-1}+$ essential amino acids); 20 aa (synthetic oviduct fluid with $8 \mathrm{mg} \mathrm{BSA} \mathrm{ml}^{-1}+$ 1 mmol glutamine $\mathrm{I}^{-1}+$ non-essential + essential amino acids). Values with the same letter are significantly different; $P<0.05$. Data from Steeves and Gardner (1997).

culturing mouse zygotes in protein-free medium for 4 days, by which time more than $80 \%$ of the embryos should have reached the expanded blastocyst stage.

\section{Assessment of Embryo Viability}

Assessment of embryo viability in culture is rather subjective: gross embryo morphology is used as the most common method for selecting embryos for transfer. The ability to identify the most viable embryos from within a given cohort should increase the overall success of assisted reproductive procedures. There are several comprehensive reviews on the suitability of viability tests for embryos (Rieger, 1984; Gardner and Leese, 1993; Overstrom, 1996). Here, those methods most likely to identify viable embryos before transfer are discussed.

\section{Nutrient uptake and energy metabolism}

In light of the significance of embryo metabolism to the developing embryo in culture, it is worth considering the potential of quantitating metabolism to assess embryo viability before transfer. Renard et al. (1980) observed that day 10 cattle blastocysts that had a glucose uptake higher than $5 \mu \mathrm{g}$ $\mathrm{h}^{-1}$ developed better both in culture and in vivo after transfer than blastocysts with a glucose uptake below this value. However, due to the insensitivity of the spectrophotometric method used they were not able to quantify glucose uptake by earlier stage embryos. Rieger (1984) showed that morphologically normal day 7 cattle blastocysts took up significantly more radiolabelled glucose than did degenerating blastocysts, and proposed that embryonic metabolism may be a suitable 

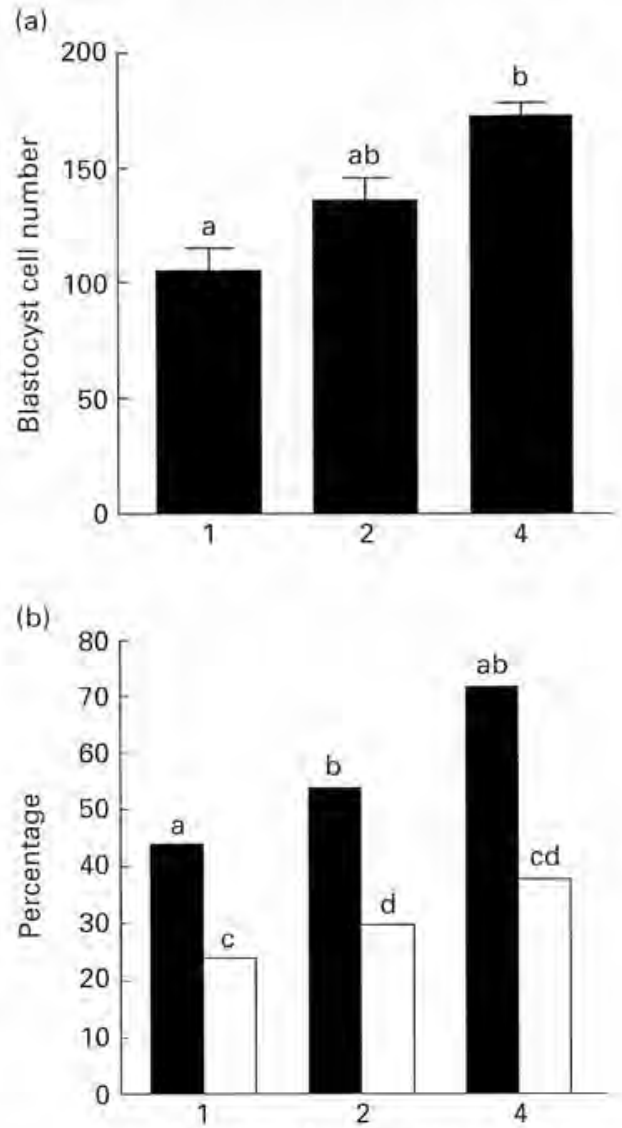

Number of embryos per drop

Fig. 4. (a) Effect of culturing sheep embryos in groups. Sheep zygotes were cultured individually, or in groups of two or four, in 20 $\mu \mathrm{l}$ of synthetic oviduct fluid with $8 \mathrm{mg}$ BSA $\mathrm{ml}^{-1}+20$ amino acids (SOFaa). Values with the same letter are significantly different; $a$, $P<0.05 ; \mathrm{b}, P<0.01$. Data from Gardner $e t$ al. (1994). (b) Effect of culturing bovine embryos in groups. Percentage blastocyst development (closed bars) and percentage of inner cell mass/total number of cells (open bars). Bovine embryos were cultured in groups of 50 in $500 \mu \mathrm{l}$ of medium SOFaa at $39^{\circ} \mathrm{C}$, in $7 \%$ $\mathrm{O}_{2}, 5 \% \mathrm{CO}_{2}$ and $88 \% \mathrm{~N}_{2}$ for $72 \mathrm{~h}$. After this time embryos with more than 8 cells were transferred to $50 \mu \mathrm{l}$ drops of SOFaa for a further $72 \mathrm{~h}$ of culture. Embryos were cultured singly or in groups of two or four. Values with the same letters are significantly different; $P<0.05$. Data from Ahern and Gardner (1998). 


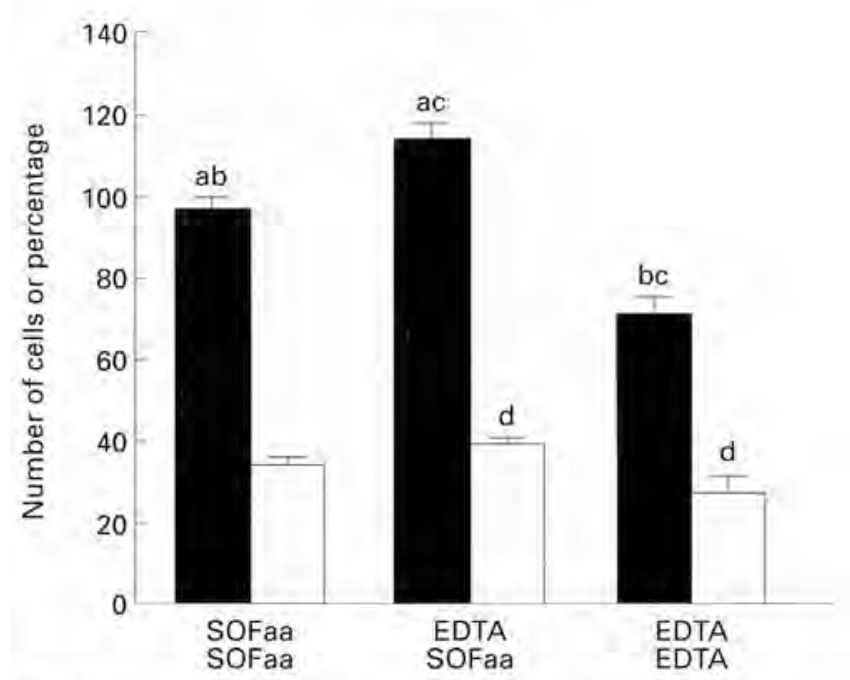

Fig. 5. Number of bovine blastocyst cells (solid bars) and percentage of inner cell mass/total number of cells (open bars). Bovine embryos, obtained from in vitro maturation and in vitro fertilization, were cultured for the first $72 \mathrm{~h}$ in either SOFaa (synthetic oviduct fluid with $8 \mathrm{mg} \mathrm{BSA} \mathrm{ml}^{-1}+$

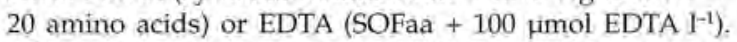
After $72 \mathrm{~h}$, embryos at about the 8- to 16-cell stage were transferred to fresh medium. Values with the same letter are significantly different; $P<0.01$. Data from Gardner $e t$ al. (1997b).

method for assessing viability before transfer. With the application of non-invasive microfluorescence, it became possible to quantify glucose uptake by individual day 4 mouse blastocysts before transfer to recipient females (Gardner and Leese, 1987). The embryos that went to term were found to have a significantly higher glucose uptake in culture than embryos that failed to develop after transfer. Unfortunately these studies were retrospective and therefore could not demonstrate conclusively whether it was possible to identify viable embryos before transfer using metabolic criteria.

However, a study on day 7 cattle blastocysts before and after cryopreservation showed that it was possible to identify blastocysts capable of re-expansion in the hours immediately after thawing. Blastocysts that survived the freeze-thaw procedure had a significantly higher glucose uptake and lactate production than those embryos that did not re-expand and subsequently died (Gardner et al., 1996b; Fig. 6). The significance of this study is that there was no overlap in the distribution of glucose uptake by the viable and non-viable embryos. Thus it may indeed be possible to use metabolic criteria for prospective selection of viable embryos. Lane and Gardner (1996) therefore performed a prospective trial in which day 5 mouse blastocysts were classified as either viable or non-viable according to their glycolytic activity. Glucose consumption and lactate production were measured in individual blastocysts of equivalent morphology and the same diameter. It was observed that although the blastocysts had the same appearance, there was a great difference between metabolic profile of blastocysts, confirming that morphology is a poor criterion upon which to base embryo selection (Gardner and Lane, 1997; Lane and Gardner, 1997b). A hypothesis was established in which blastocysts with glycolytic activity similar to that of an in vivo developed blastocyst, that is a high rate of glucose consumption but low lactate production, were deemed to be the most viable 
(a)

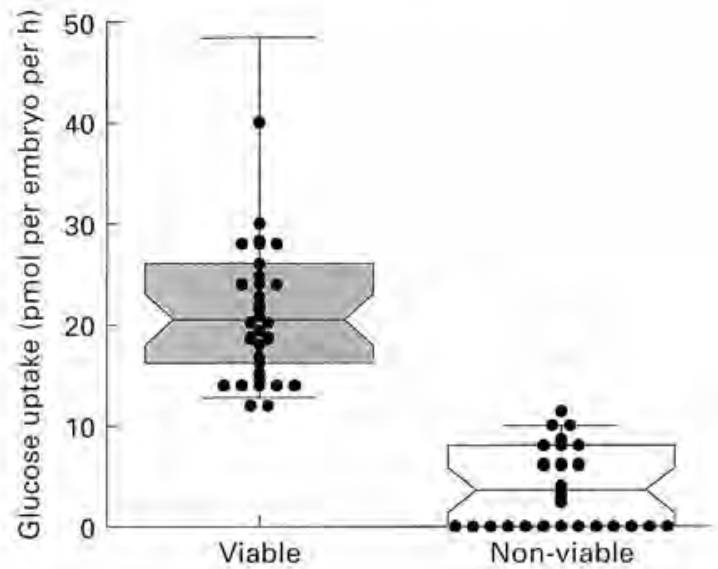

(b)

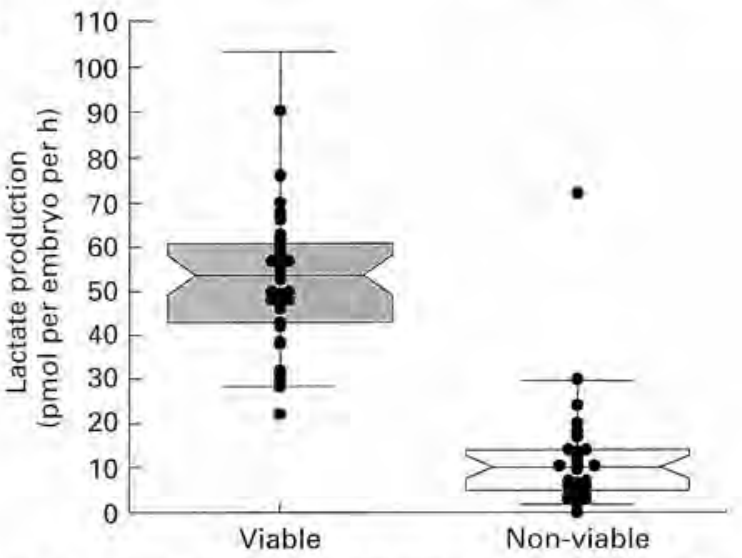

Fig. 6. Box plots of glucose uptake (a) and lactate production (b) by individual bovine blastocysts after thawing. Blastocysts were classified retrospectively as either 'viable' or 'non-viable' based upon their ability, or otherwise, to re-expand within $14 \mathrm{~h}$ after thawing. Data from Gardner et al. (1996b).

embryos. In contrast, blastocysts with a low glucose uptake and a high lactate production were deemed to be of low viability. Subsequently, metabolism of individual blastocysts was assessed before transfer. The control for this study was blastocysts transferred on the basis of morphology alone. Fetal development per blastocyst transferred in the control group was $20 \%$, while fetal development of blastocysts classified as viable before the transfer was $80 \%$. In contrast, fetal development of blastocysts classified as having low viability was just $6 \%$. Furthermore, when the rate of glucose uptake was analysed retrospectively, it was found that embryos classified as viable had a significantly higher glucose uptake than embryos classified as non-viable. So from this study it was evident that both the rate and fate of nutrient utilization appear important.

Although abnormally high levels of glycolysis indicate a loss of viability in the mouse blastocyst, it is not clear whether glycolysis is the most suitable marker for the ruminant embryo based on the observations that sheep and cattle embryos have a much higher glycolytic rate than the mouse (Rieger et al., 1992; Thompson et al., 1992a; Gardner et al., 1993). Furthermore, assessment of metabolism in the mouse blastocyst is performed in a matter of hours before implantation, whereas 


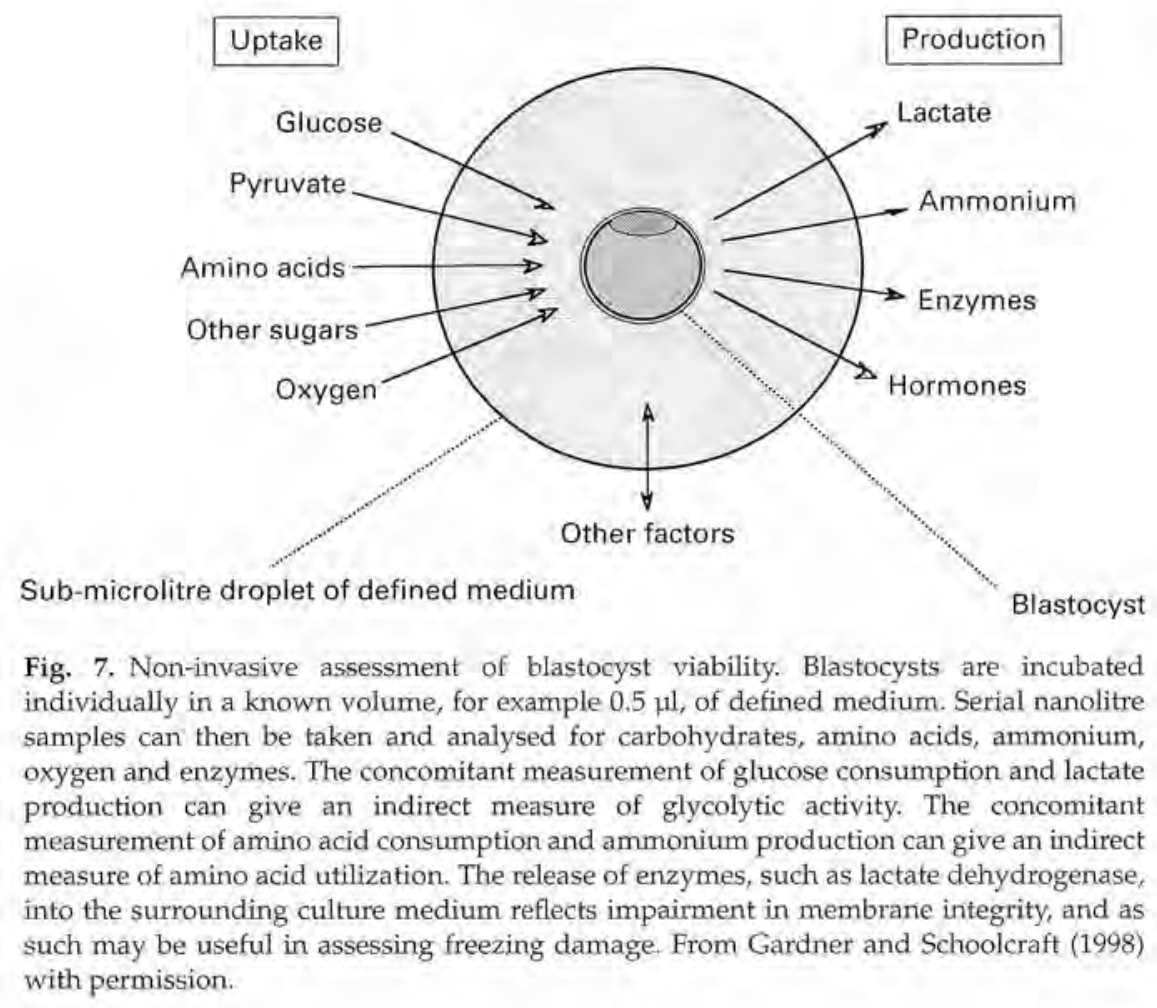

in sheep and cows, the blastocyst is routinely assessed and transferred at about day 7 , several days before implantation occurs. It is most likely that due to the plasticity of the embryo, a single marker of viability will have limited potential. It is therefore proposed that several markers be used in parallel to assess development potential before transfer (see below and Fig. 7).

\section{Oxygen uptake}

With the development of both multichannel embryo microrespiration systems (Overstrom, 1996) and fluorometric assays (Thompson et al., 1996), it is now possible to quantify oxygen consumption by individual and small groups of cattle embryos non-invasively. Such procedures will be invaluable in assessing mammalian embryo metabolism and respiration. Whether oxygen consumption by embryos is correlated with developmental potential has yet to be determined. It is envisaged that this approach will be most applicable in conjunction with the assessment of nutrient uptake, such as pyruvate or amino acids, to determine the rate and fate of the nutrient consumed.

\section{Enzyme leaknge}

A marker of plasma membrane integrity, and therefore cellular viability, is the leakage of cytosolic enzymes into the surrounding medium. Johnson et al. (1991) used such an approach to assess the developmental capacity of day 6.5 to 7.5 cattle embryos produced in vivo after culture for $24 \mathrm{~h}$. There was a significant inverse relationship between the appearance of the enzyme lactate dehydrogenase (LDH) in the surrounding culture medium and embryo development, that is embryos that failed to develop released significantly more LDH into the medium. Whether this 
approach can be used prospectively to select viable embryos has yet to be determined. However, such an approach may be significant in the comparison of different cryopreservation procedures, specifically their induction of membrane damage.

\section{Hormone and growth factor production}

Hernandez-Ledmezma et al. (1993) have shown that the production of trophoblast interferon by cattle blastocysts was determined by both the developmental stage and quality of the embryo. Such an approach is by default more specific than general metabolism, and as such may be useful in determining appropriate levels of genome activation, which in turn may reflect subsequent viability.

\section{Conclusions}

The physiology of the mammalian embryo undergoes considerable changes during the preimplantation period. Concomitantly, the embryo exhibits changes in its nutrient requirements and metabolism. The application of sequential media or perfusion culture enables the changing requirements of the embryos to be met. The use of such gradient culture systems appears to induce less stress on the embryo, thereby maintaining high levels of viability. As culture of the in vivo fertilized embryo gives rise to more blastocysts than the culture of embryos derived from in vitro maturation and in vitro fertilization (Thompson et al., 1995), it may be appropriate to focus more on maturation and fertilization conditions, both of which have a significant impact on subsequent embryo development (De Matos et al., 1995; Earl et al., 1997).

First and foremost I would like to thank Paul Batt for his endless enthusiasm and encouragement. Without Paul our ruminant endeavours would never have succeeded. Sincerest thanks to Lisa Maclellan, Tracey Steeves and Tim Ahern for their dedication to the cause, and to Drs Jeremy Thompson and Michelle Lane for their comments on this manuscript and for keeping the fire burning.

\section{References}

Ahern TJ and Gardner DK (1998) Culturing bovine embryos in groups stimulates blastocyst development and cell allocation to the inner cell mass Theriogenology 49194 (Abstract)

Balt PA, Gardner DK and Cameron AWN (1991) Oxygen concentration and protein source affect the development of preimplantation goat embryos in vitro. Reproduction Fertility and Development 3 601-607

Behboodi E, Anderson GB, BonDurant RH, Cargill SL, Kreuscher BR, Medrano JF and Murray JD (1995) Birth of large calyes that developed from in vitro-derived bovine embryos Theriogenology 44 227-232

De Matos DG, Furnus CC, Moses DF and Baldassarre H (1995) Effect of cysteamine on glutathione level and developmental capacity of bovine oocytes matured in vitro. Molecular Reproduction and Dovelopnevit 42 432-436

Earl CR, Kelly J, Rowe J and Armstrong DT (1997) Glutathione treatment of bovine sperm enhances in sitro blastocyst production rates Theriogeitology 47255 (Abstract)

Edwards LE, Batt PA, Gandolfi F and Gardner DK (1997) Modifications made to culture medium by bovine oviduct epithelial cells: changes to carbohydrates stimulate bovine embryo development Mofecular Reproduction and Devielopment 46 146-154

Fischer B and Bavister BD (1993) Oxygen tension in the oviduct and uterus of rhesus monkeys, hamsters and rabbits loumal of Reproduction and Fertility 99 673-679
Gandolf F and Moor RM (1987) Stimulation of early embryonic development in the sheep by coculture with oviduct cells Journal of Reproduction and Fertility 81 23-28

Gardner DK (1994) Culture of mammalian embryos in the absence of serum and somatic cells Cell Biology International 18 1163-1179

Gardner DK (1998a) Changes in requirements and utilization of nutrients during mammalian preimplantation embryo development and their significance in embryo culture Theriogenology 49 83-102

Gardner DK (1998b) Embryo development and culture techniques. In Animal Breeding: Teclmology for the 27st Century pp13-46 Ed. I Clark, Harwood Academic Publishers, London

Gardner DK and Lane M (1993a) Embryo culture systems. In Handbook of In Vitro Fertilization pp 85-114 Eds A Trounson and DK Gardner. CRC Press, Boca Raton

Gardner DK and Lane M (1993b) Amino acids and ammonium regulate the development of mouse embryos in culture Biology of Reproduction 4 377-385

Gardner DK and Lane M (1996) Alleviation of the "2-cell block" and development to the blastocyst of $\mathrm{CF} 1$ mouse embryos: role of amino acids. EDTA and physical factors Himam Reproduction 11 2703-2712

Gardner DK and Lane M (1997) Culture and selection of viable blastocysts: a feasible proposition for human IVF? Himian Reproduction Lpdate 3 367-382 
Gardner DK and Leese HJ (1987) Assessment of embryo viability prior to transfer by the non-invasive measurement of glucose uptake Journal of Experimental Zoology 242 10́-105

Gardner DK and Leese HJ (1993) Assessment of embryo metabolism and viability. In Handbook of in Vitro Fertilization pp 195-211 Eds A Trounson and DK Gardner. CRC Press, Boca Raton

Gardner DK and Schoolcraft WB (1998) Elimination of high order multiple gestations by blastocyst culture and transfer, In Female Infertility Therapy: Current Practice pp 267-274 Eds Z Shoham, C Howles and H Jacobs. Martin Dunnitz, London

Gardner DK, Lane M and Batt PA (1993) The uptake and metabolism of pyruvate and glucose by individual preattachment sheep embryos developed in vivo. Molecular Reproduction and Development 36 313-319

Gardner DK, Lane M, Spitzer A and Batt PA (1994) Enhanced rates of cleavage and development for sheep zygotes cultured to the blastocyst stage in vitro in the absence of serum and somatic cells: amino acids, vitamins and culturing embryos in groups stimulate development Biology of Reproduction 50 390-400

Gardner DK, Lane M, Calderon I and Leeton J (1996a) The environment of the human embryo in vizo: analysis of oviduct and uterine fluids during the menstrual cycle and metabolism of cumulus cells Eertility and Sterility 65 349-353

Gardner DK, Pawelczynski M and Trounson A (1996b) Nutrient uptake and utilization can be used to select viable day 7 bovine blastocysts after cryopreservation Molecular Reproduction and Development 44 472-475

Gardner DK, Lane M and Rodriguez-Martinez H (1997a) Fetal development after transfer is increased by replacing protein with the glycosaminoglycan hyaluronate for embryo culture Human Reproduction 12 Abstract Book 1, O-215 (Abstract)

Gardner DK, Lane MW and Lane M (1997b) Bovine blastocyst cell number is increased by culture with EDTA for the 72 hours of development from the zygote Theriogenology 47 278 (Abstract)

Gardner DK, Lane MW and Lane M (1997c) Development of the inner cell mass in mouse blastocysts is stimulated by reducing the embryoincubation volume ratio Human Reproduction 12 Abstract Book 1 P-132

Gardner DK, Vella P, Lane M, Wagely L, Schlenker T and Schoolcraft WB (1998) Culture and transfer of human blastocysts increases implantation rates and reduces the need for multiple embryo transfers Fertility and Sterility 69 $84-88$

Hernandez-Ledmezma JJ, Mathialagan N, Villanueva C, Sikes JH and Roberts RM (1993) Expression of bovine trophoblast interferons by in vitro-derived blastocysts is correlated with their morphological quality and stage of development Molecular Reproduction and Development 36 1-6

Johnson SK, Jordan JE, Dean RG and Page RD (1991) The quantification of bovine embryo víability using a bioluminescent assay for lactate dehydrogenase Theriogenology 35 425-433

Kano K, Miyano T and Kato S (1998) Effects of glycosaminoglycans on the development of in vitro matured and fertilized porcine oocytes to the blastocyst stage in sitro. Biology of Reproduction 58 1226-1232
Keskintepe L and Brackett BG (1996) In vitro developmental competence of in vitro-matured bovine oocytes fertilized and cultured in completely defined media Biology of Reproduction $55333-339$

Keskintepe L, Burnely CA and Brackett BG (1995) Production of viable bovine blastocysts in defined in titro conditions Biology of Reproduction 52 1410-1427

Lane M and Gardner DK (1992) Effect of incubation volume and embryo density on the development and viability of mouse embryos in vitro. Human Reproduction $7558-562$

Lane M and Gardner DK (1996) Prospective selection of viable mouse embryos prior to transfer using metabolic rate Human Reproduction 11 1975-1978

Lane M and Gardner DK (1997) Differential regulation of mouse embryo development and viability by amino acids Journal of Reproduction and Fertility 109 153-164

Lawitts JA and Biggers JD (1992) Joint effects of sodium chloride, glutamine, and glucose in mouse preimplantation embryo culture media Molecular Reproduction and Development 31 189-194

Leese HJ (1991) Metabolism of the preimplantation mammalian embryo, In Oxford Revieus of Reproductive Biology 13 35-72

Liu Z and Foote RH (1995) Effects of amino acids on the development of in-vitro matured/im-vitro fertilized bovine embryos in a simple protein-free medium Human Reproduction 11 2985-2991

Mastroianni L, Jr and Jones R (1965) Oxygen tension within rabbit fallopian tube Journal of Reproduction and Fertility 9 99-102

Miller JGO and Schultz GA (1987) Amino acid content of preimplantation rabbit embryos and fluids of the reproductive tract Biology of Reproduction 36 125-129

Moses DF, Matkovic M, Cabrera Fisher E and Martinez AG (1997) Amino acid contents of sheep oviductal and uterine fluids Theriogenology 47336 (Abstract)

Nichol R, Hunter RHF, Gardner DK, Leese HJ and Cooke GM (1992) Concentration of energy substrates in porcine oviduct fluid and blood plasma during the peri-ovulatory period Joumal of Reproduction and Fertility $96699-707$

O'Neill C (1997) Evidence for the requirement of autocrine growth factors for the development of mouse preimplantation embryos in vitro. Biology of Reproduction $\mathbf{5 6}$ 229-237

Overstrom EW (1996) In vitro assessment of embryo viability Theriogenology 45 3-16

Paria PC and Dey SK (1990) Preimplantation embryo development in vitro: cooperative interactions among embryos and role of growth factors Procecdings of the National Academy of Sciences, USA 87 3756-3760

Pinyopummintr T and Bayister BD (1991) In vitro matured/in vitro fertilized bovine oocytes can develop into morulae/blastocysts in chemically defined, protein-free culture media Biology of Reproduction 45 736-742

Pinyopummintr I and Bavister BD (1996) Energy substrate requirements for in vitro development of early cleavagestage bovine embryos Molecular Reproduction and Developmenl 44 193-199

Renard JP, Philippon A and Menezo Y (1980) In vitro uptake of glucose by bovine blastocysts fournal of Reproduction and Fertility 58 161-164

Restall BJ and Wales RG (1966) The Fallopian tube of the sheep III. The chemical composition of the fluid from the Fallopian tube Australian Journal of Biological Science $19687-698$

Rieger D (1984) The measurement of metabolic activity as an 
approach to evaluating viability and diagnosing sex in early embryos Theriogenology/ 21 138-149

Rieger D (1992) Relationship between energy metabolism and development of the early embryo Theriogenology 37 75-93

Rieger D, Loskutoff NM and Betteridge KJ (1992) Developmentally related changes in the metabolism of glucose and glutamine by cattle embryos produced and co-cultured in vitro. Journal of Reproduction and Fertility $95,585-595$

Rosenkrans CF, Jr and First NL (1994) Effect of free amino acids and vitamins on cleavage and developmental rate of bovine zygotes in vitro, journal of Animal Science $72434-437$

Sakkas D, Batt PA and Cameron WN (1989) Development of preimplantation goat (Capra hircus) embryos in vivo and in vitro. Journal of Reproduction and Fertility 87 359-365

Steeves TE and Gardner DK (1997) Temporal effects of amino acids on bovine embryo development in culture Biology of Reproduction 57 (Supplement 1) 25 (Abstract)

Tervit HR, Whittingham DG and Rowson LEA (1972) Successful culture in vitro of sheep and cattle ova Journal of Reproduction and Fertility 30 493-497

Thompson JG (1996) Defining the requirements for bovine embryo culture Theriogenology $4527-40$

Thompson JGE, Simpson AC, Pugh PA, Donnelly PE and Tervit HR (1990) Effect of oxygen concentration on in-vitro development of preimplantation sheep and cattle embryos Journal of Reproduction and Fertility 89 573-578

Thompson JG, Simpson AC, Pugh PA and Tervit HR (1992a) Requirement for glucose during in vitro culture of sheep preimplantation embryos Molecular Reproduction and Development 31 253-257
Thompson JG, Simpson AC, Pugh PA and Tervit HR (1992b) In vitro development of early sheep embryos is superior in medium supplemented with human serum compared with sheep serum or human serum albumin Arimal Reproduction Science 29 61-68

Thompson JG, Gardner DK, Pugh PA, McMillan J and Tervit RH (1995) Lamb birth weight following transfer is affected by the culture system used for pre-elongation development of embryos Biology of Reproduction 53 1385-1391

Thompson JG, Partridge RJ, Houghton FD, Cox Cl and Leese H] (1996) Oxygen uptake and carbohydrate metabolism by in vitro derived bovine embryos lournal of Reproduction and Fertility 106 299-306

Thompson JG, Sherman ANM, Allen NW, McGowan LT and Tervit HR (1998) Total protein content and protein synthesis within pre-elongation stage bovine embryos Molecular Reproduction and Development 50 139-145

Tiffin GJ, Rieger D, Betteridge KJ, Yadav BR and King WA (1991) Glucose and glutamine metabolism in pre-attachment cattle embryos in relation to sex and stage of development Journal of Reproduction and Fertility 93 125-132

Walker SK, Heard TM and Seamark RF (1992) In vitro culture of sheep embryos without co-culture: success and perspectives Theriogenology 37 111-126

Wiemer KE, Watson AJ, Polanski V, McKena AI, Fick GH and Schultz GA (1991) Effects of maturation and co-culture treatments on the development capacity of early bovine embryos Molecular Reproduction and Development 30 $330-338$ 